\title{
Outcome of fecal incontinence in the two-staged seton fistulotomy for complex fistula in Ano.
}

1. MBBS, FCPS

Registrar General Surgery Shaikh Zayed Hospital Lahore.

2. MBBS, MS

Registrar General Surgery

Shaikh Zayed Hospital Lahore.

3. MBBS, FRCS

Professor of General

Shaikh Zayed Hospital Lahore.

4. MBBS, FCPS

Assistant Professor General Surgery Shaikh Zayed Hospital Lahore.

5. MBBS, FCPS

Senior Registrar, General Surgery

Shaikh Zayed Hospital Lahore.

6. MBBS, FCPS

Professor of General Surgery

Shaikh Zayed Hospital Lahore.

7. MBBS, FCPS

Associate Professor of General Surgery

Shaikh Zayed Hospital Lahore.

Correspondence Address:

Dr. Rabia Ikram

Department of General Surgery

Shaikh Zayed Hospital Lahore.

drrabiaikram@hotmail.com

Article received on:

28/01/2019

Accepted for publication:

24/04/2021
Rabia Ikram ${ }^{1}$, Shafique ur Rehman², Haroon Javaid Majid³ ${ }^{3}$ Arif Javed ${ }^{4}$, M. Aamir Jamil ${ }^{5}$, Harun Majid Dar ${ }^{6}$, M. Shafi $^{7}$

ABSTRACT... Objective: To determine the frequency of fecal incontinence in the two-staged Seton fistulotomy in complex fistula in ano. Study Design: Prospective Cohort study. Setting: Surgical Out-patient Department at Shaikh Zayed Hospital Lahore. Period: September 2015 till March 2016. Material \& Methods: After ethical review board approval, data was collected from 100 patients who fulfilled the inclusion criteria. All the procedures were conducted in the lithotomy position, under spinal or general anesthesia. A rigid sigmoidoscopy and proctoscopy was done prior to intervention. Fistula tract was marked using hydrogen peroxide $\left(\mathrm{H}_{2} \mathrm{O}_{2}\right)$ for the identification of the internal opening. The external opening was gently probed using a standard $3 \mathrm{~mm}$ blunt-tipped probe till the internal opening was reached. The portion of the track outside the sphincter mechanism and any lateral tracts were laid open. A feeding tube of size 5 French was loosely tied around the remaining muscular portion of the sphincter complex. The seton was left in place for six weeks followed by secondary fistulotomy. Patients were evaluated for incontinence one month after the second procedure. Results: In our study, mean age was calculated as $47.38+10.96$ years, $73 \%(n=73)$ were male and $27 \%(n=27)$ were females, frequency of fecal incontinence in the two-staged Seton fistulotomy in complex fistula in ano was recorded in $17 \%(n=17)$. Conclusion: The frequency of fecal incontinence in the twostaged seton fistulotomy for complex fistula in ano was acceptable in our study population and in tandem with literature. The procedure may be a suitable alternative to loose-seton placement alone.

Key words: $\quad$ Complex Fistula in ANO, Fecal Incontinence, Two-Staged Seton Fistulotomy.

Article Citation: Ikram R, Shafique ur Rehman, Majid HJ, Javed MA, Jameel MA, Dar HM, Shafi M. Outcome of fecal incontinence in the two-staged seton fistulotomy for complex fistula in Ano. Professional Med J 2021; 28(8):1061-1066. https://doi.org/10.29309/TPMJ/2021.28.08.3187

\section{INTRODUCTION}

A fistula-in-ano is a persistent abnormal tract with an external opening at the perianal skin and internal opening in anal canal. The tract forms a communication of the skin with the rectum or anus internally. This tract may be singular or multiple tracts may exist and both internal and external opening may be multiple or single. ${ }^{1}$ Symptoms are worrisome due to the effect they have on quality of life, and range from mild tenderness and malaise to purulent discharge with resultant hygienic problems and may exacerbate to local sepsis with certain underlying conditions. ${ }^{2}$

The aim of the surgical treatment is twofold therein to prevent recurrences following operative treatment and to conserve fecal continence.
Majority of anal fistulas are classified as simple and require a mere fistulotomy for treatment. ${ }^{3}$ However, treatment of complex anal fistula remains a significant surgical challenge. Complex perianal fistulas such as high trans-sphincteric fistula, supra-sphincteric fistulas, anteriorly lying tract in females, and those where more than $30 \%$ of external sphincter complex is compromised would require division of large portions of the external sphincter resulting in higher fecal incontinence.

Many procedures have been devised in an attempt to minimize this and optimize the treatment. Sphincter division procedures are cutting Seton and two-staged Seton fistulotomy. 


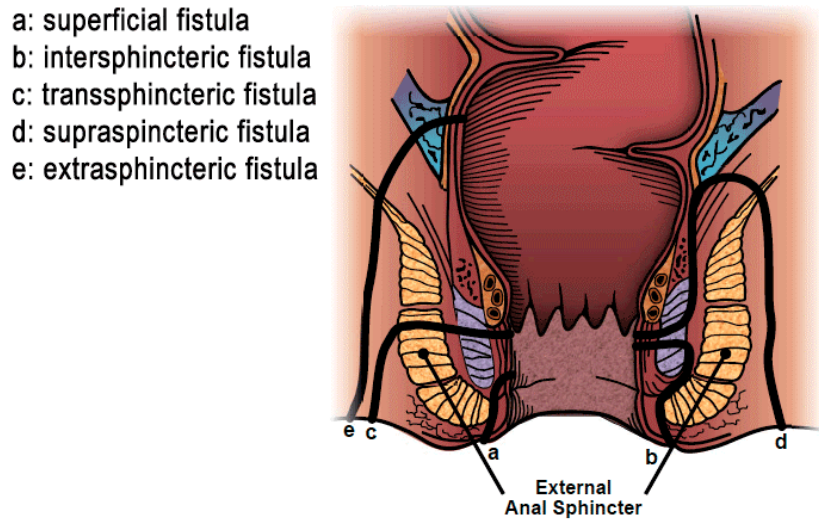

Figure-1. Diagrammatic representation of types of fistula-in-ano.

Sphincter conserving procedures are fibrin glue, advancement flaps and LIFT technique. Nevertheless, there is no established surgical procedure that is superior to the rest due to variable outcomes in terms of cure and incontinence and largely studies have identified a surgeon's bias. ${ }^{4}$

Among sphincter division procedures, surgeons historically preferred two-staged fistulotomy in lieu of cutting Seton as the technique was thought to produce less pain and divided the sphincter in a controlled fashion thus entailing better continent outcomes. The two-staged fistulotomy technique has variable results in the literature. GarciaAguilar showed major incontinence rates of $25 \%$ while Bokhari et al. showed major incontinence rates of $14 \% .^{4,5}$ This is a clinically remarkable difference produced with the same technique and merits questioning of where the true major incontinence rates lie with the procedure and if they are reproducible independent of the surgeon as a variable.

In this study, we evaluated two-staged fistulotomy for complex perianal fistulas in terms of frequency of incontinence. The rationale of the study was to generate outcomes using local data and to compare it with variable rates of incontinence present in the literature.

\section{MATERIAL \& METHODS}

The study conducted was a prospective cohort in the Department of General Surgery at Shaikh Zayed Hospital, Lahore from September 2015 till
March 2016 after the approval of ethical committee. We included 100 participants and sample size was calculated using a 95\% confidence level, $7 \%$ margin of error taking an expected percentage of fecal incontinence as $14 \%^{4}$ for sample calculation. We enrolled all patients with complex perianal fistula that was trans-sphincteric diagnosed on clinical examination followed by confirmatory fistulogram delineating complete tract pathology, including those cases that were recurrent.

The excluded cases were those with preoperative fecal incontinence based on history and examination, Crohn's disease, ano-rectal malignancy and therapeutic radiation exposure to the pelvis. All the procedures were done under spinal or general anesthesia and in the lithotomy position.

A rigid sigmoidoscopy and proctoscopy was done prior to intervention. Fistula tract was marked using hydrogen peroxide $\left(\mathrm{H}_{2} \mathrm{O}_{2}\right)$ for the identification of the internal opening. The external opening was gently probed using a standard 3 $\mathrm{mm}$ blunt-tipped probe till the internal opening was reached and identified. The portion of the track outside the sphincter mechanism and any lateral tracts were laid open. A feeding tube sized French 5 was loosely tied around the remaining muscular portion of the sphincter complex. The seton was left in place for six weeks followed by a secondary fistulotomy. Patient was evaluated for incontinence one month after the second procedure. All this information was recorded in a pre-designed proforma and SPSS version 16 was used for data analysis.

\section{RESULTS}

We found our age distribution to be $63 \%(n=63)$ were between $15-50$ years of age while $37 \%$ $(n=37)$ were between $51-70$ years of age, and the mean age was $47.38+10.96$ years. (Table-I.)

Gender distribution showed $73 \%(n=73)$ of our participants were male and $27 \%(n=27)$ were female. (Table-II.)

Frequency of fecal incontinence was found to be $17 \%(n=17)$ while $83 \%(n=83)$ did not develop 
this post-operative morbidity. (Table-III.)

\begin{tabular}{|c|c|}
\hline Age(in years) & No. of Patients \\
\hline $15-50$ & $63(63 \%)$ \\
\hline $51-70$ & 37 (37\%) \\
\hline Total & $100(100 \%)$ \\
\hline Mean+SD & $47.38+10.96$ \\
\hline \multicolumn{2}{|c|}{ Table-I. Age distribution. $(\mathrm{N}=100)$. } \\
\hline Gender & No. of Patients \\
\hline Male & $73(73 \%)$ \\
\hline Female & 27 (27\%) \\
\hline Total & $100(100 \%)$ \\
\hline \multicolumn{2}{|c|}{ Table-II. Gender distribution. $(\mathrm{N}=100)$} \\
\hline Incontinence & No. of Patients \\
\hline Yes & 17 (17\%) \\
\hline No & $83(83 \%)$ \\
\hline Total & $100(100 \%)$ \\
\hline \multicolumn{2}{|c|}{$\begin{array}{l}\text { Table-III. Frequency of fecal incontinence in the two } \\
\text { staged seton fistulectomy in complex fistula in ano. } \\
\qquad(n=100)\end{array}$} \\
\hline
\end{tabular}

\section{DISCUSSION}

Perianal fistulas and their optimal treatment have remained evasive over time. A meta-analysis done by Gottgens, found that even between advancement flaps, different types of Seton, fibrin glue, fistula plugs and techniques such as island flaps or LIFT procedure there was no clear superior method and that perhaps far more studies would be needed to cohesively accumulate results and perhaps delineate a technique that proves to be superior both statistically and clinically. This would entail a technique that not only proves to be the least damaging to the sphincter complex, but also has the least recurrence rate, pain profile and earlier healing rates. ${ }^{6}$

Another meta-analysis done pointed out that flaps and glues may have lower incontinence rate, however glues and plugs may come at the cost of higher recurrence as well. This remains a modest challenge for the surgeon, which outcome would they rather endure in practice. They further found that different approaches to seton placement was used, where conventional cutting setons that divided the sphincter mechanism and those setons that are traversed through the intersphincteric space to preserve the internal anal sphincter had little difference between the two approaches in terms of recurrence and incontinence. ${ }^{7}$

In our study, out of 100 participants with complex perianal fistula, frequency of fecal incontinence in the two staged seton fistulotomy in complex fistula in ano was recorded in $17 \%$, that is of the 100 participants only 17 developed fecal incontinence. This was comparable to the $14 \%$ we had anticipated using previous studies, and a $3 \%$ difference between fecal incontinence rate is clinically significant in showing that the variation might not be as vast as that literature suggested and may lie in a similar ballpark range. Whereas one study had initially shown a rate of incontinence as high as $25 \%$, our findings are more in tandem with a lower incontinence rate and one that may be acceptable for the nature of surgery, where the sphincter complex is being handled. ${ }^{4,5}$

A similar study was conducted in a Middle Eastern population where trans-sphincteric fistulas were initially laid open using a fistulotomy to the dentate line and then a cutting seton was placed around the muscular complex and on weekly tightening it allowed drainage and healing of the muscle until it reached the distal portion. The Seton used was with Silk suture. They reported greater than $90 \%$ healing rates and $15.6 \%$ incontinence, which is comparable to our study and the literature. ${ }^{8}$

Results from studies that only explored the loose Seton method without a two staged fistulotomy showed higher recurrence rates and needs for further surgical intervention and the development of local sepsis. Despite the better morbidity profile for loose Setons, it entailed the need for surgery later and thus we found that in our patients this was ameliorated by the combination of the two-staged procedure where a fistulotomy followed. Whether the fistulotomy should be done first, followed by Seton drainage and cutting or whether the reverse method may be more beneficial remains to be explored. ${ }^{9}$

Walfisch et al described a double Seton technique to avoid repeated treatments. Two silk loops are 
passed through the tract. One of these is tied at the time of surgery while the second is left in place to be tied usually a month later, at which time the first loop is removed. ${ }^{10}$ This method would use the aid of a seton for a considerably longer period of time. We felt that the two staged setonfistulotomy technique is advantageous in that repeated seton placements and tightening are not necessary, with the first placement resulting in muscle-sparing healing and a second procedure resulting in a simple fistulotomy for secondary intention healing and closure.

Theerapol et al described a method wherein two-setons are used however they have varying function such that one is used for drainage and loosely tied, while the other is used for purposes of cutting to encourage fibrosis and healing of the tract. García Olmo et al described the multiple Seton technique wherein five sutures are passed along the fistuluous track. As one suture comes down and loosens, the other is tightened and was undertaken on a weekly basis for a period of five weeks. ${ }^{11}$ Durgun et al described the use of multiple modified cutting Setons along with a partial fistulotomy; insomuch that the fistula tract is laid open with the aid of a specialized probe up till the dentate line. ${ }^{12}$ The literature is replete with multiple modifications and techniques to aim for the same outcome. Though this author understands that the use of multiple setons and with different functions such as cutting and drainage have their advantages of decreased morbidity of an incision. However, we felt that our seton placement had a better profile in terms of decreased pain as the loosely tied seton managed to achieve drainage and the minimal cutting and fibrosis that we had hoped it would achieve, followed by the fistulotomy.

Two-stage seton fistulotomy is widely practiced. Conceptually, the seton is placed to promote fibrosis of the tract and initiate primary healing, followed by interval splitting of the sphincter to spare the amount of the sphincter complex that would have had to be sacrificed if it were not done in a staged fashion. However, similar to any anorectal procedure there is a risk of fecal incontinence that in part may be mitigated by the technique used and in part by experienced hands. ${ }^{9,13,14}$

Seton material in itself has been studied though not widely to assess differences. Silk, Penrose drains, natural caustic plants, horsehair, metallic wires, rubber, even surgical gloves have all been used to create a seton. ${ }^{15} \mathrm{~A}$ study compared loose silk Seton and a cutting Seton made from prolene, wherein they found that though little difference occurred in terms of recurrence and fecal continence, there was far more pain experienced with the prolene seton. ${ }^{16}$ The study where surgical glove strip was used as a seton material found $24.1 \%$ incontinence rates however, of these only $5.4 \%$ were liquid stool, the rest were all incontinence to flatus. ${ }^{17}$ Another study undertook silicone based seton that was tightly tied to the muscle complex, here they found $25 \%$ incontinence rates which is comparable to some other studies that used cutting setons alone. ${ }^{18}$ A survey conducted though found that in most surgical practice more than $70 \%$ of surgeons used silicone setons followed by silk sutures. This likely demonstrates that most of our data present on materials would be including these two materials. Inherent to this is the deduction that silicone and Silk achieve adequate drainage and are preferable for loose setons which have now become the acceptable practice in most centers as compared to cutting setons. ${ }^{19}$ Besides seton materials, different techniques to avoid seton tightening such as clip applicators are also being studies and different methods to place the seton. ${ }^{20}$ However, at the end the material of the seton and the method of application all remain statistically non-significant in terms of outcomes of recurrence and continence, thus; silicone or silk based loose setons seems to be the preferable method by and large.

In our study we found an acceptable rate of incontinence and one that was anticipated at the lower end of the range of fecal incontinence odds, thus making it a procedure that may be utilized and adopted more widely in practice for complex fistula in ano. 


\section{CONCLUSION}

We concluded that the frequency of fecal incontinence in the two-staged seton fistulotomy in complex fistula in ano is comparable to the lower range odds of developing fecal incontinence after this procedure.

There is a wide variability in the literature and this would require larger trials to accumulate data and experience to come to a standardized figure of the incidence of fecal incontinence after the staged fistulotomy procedure.

Our results are not generalizable to all complex perianal fistulas, but may be adopted for transsphincteric fistulas, and it is likely that for other types of complex fistulas the possibility of fecal incontinence may be higher.

The procedure may be a suitable alternative to loose-seton placement alone.

\section{Copyright@ 24 Apr, 2021.}

\section{REFERENCES}

1. Vasilevsky CA, Gordon PH. Benign anorectal: Abscess and fistula. In: Wolff BG, Fleshman JW, Beck DE, Pemberton JH, Wexner SD, eds. The ASCRS Textbook of Colon and Rectal Surgery. New York, NY: Springer; 2007: Chapter 13.

2. Williams JG, Farrands PA, Williams $A B$. The treatment of anal fistula: ACPGBI position statement. Colorectal Dis. 2007; 9:18-50.

3. PinedoMG, Caselli MG, Urrejola SG, Niklitschek LS, Molina PME, Bellolio F, et al. Modified loose seton technique for the treatment of complex anal fistulas. Colorectal Dis 2010; 12:e310-3.

4. Gottgens KW, Smeets RR, Stassen LP, Beets G, Breukink SO. Systematic review and meta-analysis of surgical interventions for high cryptoglandular perianal fistula. Int J Colorectal Dis. 2015; 30(5):583-93.

5. Cheung XC, Fahey $T$, Rogers $A C$, Pemberton $\mathrm{JH}$, Kavanagh DO. Surgical management of idiopathic perianal fistulas: A systematic review and metaanalysis. Digestive Surgery. 2021; 38(2):104-19.

6. Bokhari $S$ and Lindsey I. Incontinence following sphincter division for treatment of anal fistula. Colorectal Dis 2010; 12:e135-9.
7. Shirah $\mathrm{BH}$, Shirah HA. The impact of the outcome of treating a high anal fistula by using a cutting seton and staged fistulotomy on Saudi Arabian patients. Ann Coloproctol. 2018; 34(5):234-40.

8. Buchanan GN, Owen HA, Torkington J, Lunniss PJ, Nicholls RJ, Cohen CR. Long-term outcome following loose-seton technique for external sphincter preservation in complex anal fistula. Br J Surg. 2004; 91(4):476-80.

9. Garcia-Aguilar J, Belmonte C, Wong DW, Goldberg SM, Madoff RD. Cutting seton versus two-stage seton fistulotomy in the surgical management of high anal fistula. Br J Surg 1998; 85:243-5.

10. Walfisch S, Menachem Y, Koretz M. Double seton - a new modified approach to high transsphincteric anal fistula. Dis Colon Rectum 1997; 40:731-2.

11. García Olmo D, Vázquez Aragón P, López Fando J. Multiple setons in the treatment of high perianal fistula. Br J Surg 1994; 81:136-7.

12. Durgun V, Perek A, Kapan M. Partial fistulotomy and modified cutting seton procedure in the treatment of high extrasphincteric perianal fistulae. Dig Surg 2002; 19:56-8.

13. Pearl RK, Andrews JR, Orsay CP, et al. Role of the seton in the management of anorectal fistulas. Dis Colon Rectum. 1993; 36:573-7.

14. Kuypers HC. Use of seton in the treatment of extrasphincteric anal fistula. Dis Colon Rectum. 1984; 27:109-10.

15. Subhas G, Singh Bhullar J, Al-Omari A, Unawane A, Mittal VK, Pearlman R. Setons in the treatment of anal fistula: Review of variations in materials and techniques. Dig Surg. 2012; 29(4):292-300.

16. Celik Y, Buldanli MZ. Comparison of loose silk and tightenable polypropylene seton placement in treatment of complex anal fistula. Age. 2021; 42(12.1):43.00.

17. Chuang-Wei C, Chang-Chieh W, Cheng-Wen H, Tsai-Yu $\mathrm{L}$, Chun-Che F, Shu-Wen J. Cutting seton for complex anal fistulas. The Surgeon. 2008; 6(3):185-8.

18. Hammond TM, Knowles $\mathrm{CH}$, Porrett T, Lunniss PJ. The Snug Seton: Short and medium term results of slow fistulotomy for idiopathic anal fistulae. Colorectal Dis. 2006; 8(4):328-37. 
19. Ratto C, Grossi U, Litta F, Di Tanna GL, Parello A, b De Simone V, et al. Contemporary surgical practice in the management of anal fistula: Results from an international survey. Tech Coloproctol. 2019; 23(8):729-41.
20. Stellingwerf ME, Bak MTJ, de Groof EJ, Buskens CJ, Molenaar $\mathrm{CBH}$, Gecse KB, et al. Knotless seton for perianal fistulas: Feasibility and effect on perianal disease activity. Sci Rep. 2020; 10(1):16693.

\section{AUTHORSHIP AND CONTRIBUTION DECLARATION}

\begin{tabular}{|c|l|l|l|}
\hline Sr. \# & \multicolumn{1}{|c|}{ Author(s) Full Name } & \multicolumn{1}{|c|}{ Contribution to the paper } \\
\hline 1 & Rabia Ikram & Primary Author \\
2 & Shafique ur Rehman & Co-Author \\
3 & Haroon Javaid Majid & Co-Author \\
4 & Arif Javed & Data analysis. \\
5 & M. Aamir Jamil & Data Collection \\
6 & Harun Majid Dar & Supervisor. \\
7 & M. Shafi & Critical review.
\end{tabular}

